\title{
ANALISIS PENGELOLAAN PANGKALAN PENDARATAN IKAN (PPI) MACCINI BAJI KABUPATEN PANGKAJENE DAN KEPULAUAN
}

\author{
(Management Analysis of Maccini Baji Fish Landing Bases in \\ Pangkajene and Kepulauan Regency) \\ Oleh: \\ Asrayanti $^{1)}$, Danial ${ }^{2)}$ dan Ihsan $^{3)}$ \\ ${ }^{1)}$ Mahasiswa PS. Manajemen Pesisir dan Teknologi Kelautan PPS UMI Makassar \\ ${ }^{2)}$ PS. Ilmu Kelautan FPIK UMI Makassar \\ ${ }^{3)}$ PS. Pemanfaatan Sumberdaya Perikanan FPIK UMI Makassar
}

Korespondensi:ams.anti.asli@gmail.com

Diterima: tanggal 25 September 2018; Disetujui 13 November 2018

\begin{abstract}
Asrayanti As. Management Analysis of Maccini Baji Fish Landing Bases in Pangkajene and Kepulauan Regency. Guided by Danial and Ihsan. Study aims to analyze the improvement of the functions and infrastructure facilities of PPIs and formulate management strategies. This research was conducted in May to July 2018. The survey method was supported by primary and secondary data with a Purposive Sampling system. Data analysis is utilization analysis and SWOT analysis. The results showed that the facilities contained in the PPI Maccini Baji for pond ponds need to be dredged as deep as $2.25 \mathrm{~m}$ because they have a shallow depth of 0 meters at the lowest tide. Meanwhile, the dock is still in the form of a revetment so that in the future it is necessary to build a pier. Ice Factory Facilities and SPDN also still require additional stock to meet all the requirements around the PPI. From the results of the SWOT analysis showing the coordinates of 1.4: 1.25 which are in the quadrant I position or aggressive strategy, this condition is to support an aggressive growth policy (growth oriented strategy) by maximizing every strength possessed and utilizing existing opportunities. Strategic steps that can be taken are; developing an effective marketing system and improving service and convenience for fishermen who utilize PPI, as well as integrated licensing.
\end{abstract}

Keywords: Management, Facilities for PPI, SWOT

\begin{abstract}
ABSTRAK
Penelitian ini bertujuan menganalisis peningkatan fungsi dan kebutuhan sarana prasarana PPI serta merumuskan strategi pengelolaannya. Penelitian ini dilaksanakanpada Bulan Mei s/d Bulan Juli 2018. Metode survei yang didukung data primer dan sekunder dengan sistem PurposiveSampling. Analisis data adalah analisis pemanfaatan dan analisis SWOT.Hasil penelitian menunjukkan fasilitas yang terdapat di PPI Maccini Baji untuk kolam labuh perlu pengerukan sedalam 2,25 m karena memiliki kedalaman yang tergolong dangkal yakni 0 meter saat surut terendah. Sementara, dermaga masih berupa revetment sehingga ke depannya perlu pembangunan dermaga. Fasilitas Pabrik Es dan SPDN juga masih memerlukan penambahan stok agar dapat memenuhi semua kebutuhan di sekitar PPI. Hasil analisis SWOT menunjukkan nilai titik koordinat 1,4:1,25 yang berada pada posisi kuadran I atau strategi agresif, kondisi ini adalah mendukung kebijakan pertumbuhan yang agresif (growth oriented strategy) dengan memaksimalkan setiap kekuatan yang dimiliki dan memanfaatkan peluang yang ada. Langkah strategis yang bisa ditempuh yaitu; pengembangan sistem pemasaran yang efektif dan perbaikan layanan dan kenyamanan bagi nelayan yang memanfaatkan PPI, serta perizinan yang terintegrasi.
\end{abstract}

Kata Kunci:Pengelolaan, Fasilitas PPI, SWOT 
PENDAHULUAN

Kabupaten Pangkajene dan Kepulauan memiliki potensi perikanan yang cukup besar. Luas wilayah laut $11.464,44 \mathrm{~km}^{2}$ dan panjang total garis pantai 106,14 km wilayah Pangkep memiliki 117 pulau menjadikan Kabupaten Pangkep menjadi salah satu daerah yang mata pencaharian penduduknya terutama di daerah pulau adalah sebagian besar nelayan (Dinas Perikanan Kabupaten Pangkep, 2015). Salah satu pengembangan dalam bidang perikanan tangkap adalah dengan dibangunnya Pangkalan Pendaratan Ikan (PPI) Maccini Baji yang menjadi prioritas pengembangan dari pelabuhan tradisional menjadi kelas Pangkalan Pendaratan Ikan.Namun, pengelolaannya belum berjalan secara optimal di mana kondisinya masih berjalan di tempat padahal potensi perikanan Kabuapten Pangkep lumayan besar.Permasalahan yang ada di lokasi tersebut antara lain, fasilitas yang masih kurang memadai dan kurang lengkap termasuk kolam pelabuhan yang masih tergolong dangkal sehingga hanya bisa ditempati oleh perahu-perahu kecil saja seperti jolloro. Permasalahan dalam pengelolaan pelabuhan saat ini sangat kompleks, dimulai dari keterbatasan fasilitas, kelemahan sumber daya manusia yang menjadi pengelola serta sarana dan prasarana penunjang yang tidak memadai (Lubis, 2012 dalam Haro, 2014).

Berdasarkan hal tersebut, maka perlu adanya kajian untuk mengetahui pola manajemen dari pengelolaan PPI Maccini Baji tersebut terutama dalam hal peningkatan fungsi sarana dan prasarananya termasuk menemukan strategi pengelolaan dalam mengembangkan perannya untuk mensejahterahkan masyarakat khususnya yang bergerak di bidang perikanan.

\section{METODOLOGI}

Penelitian ini dilakukan di Pangkalan Pendaratan Ikan (PPI) Maccini Baji, Kelurahan Pundata Baji, Kecamatan Labakkang Kabupaten Pangkep. Waktu penelitian dilaksanakan pada Tanggal 14 Mei s/d tanggal 14 Juli 2018.Bahan dan alat yang digunakan untuk penelitian ini, antara lain: meteran (m), perahu, kamera, kuisioner, komputer, dan peralatan lainnya yang digunakan dalam pengumpulan dan pengolahan data-data. Dalam pengumpulan data dilakukan dengan melakukan pengukuran langsung di lapangan dimana penentuan responden dilakukan dengan menggunakan purposive sampling. Responden yang diambil adalah pihak-pihak yang terlibat langsung dalam pengelolaan PPI Maccini Baji. Pihak yang langsung terlibat dengan penyelenggaraan PPI adalah koperasi nelayan, punggawa, pedagang perantara dan produsen (nelayan/pembudidaya) dan dinas-dinas terkait yang ada.

$$
\text { Jumlah responden yang }
$$

diwawancara sebanyak 30 orang.Data yang telah dikumpulkan kemudian diolah dan dianalisis dengan menggunakan formulasi sebagai berikut: 
Panjang dermaga yang dibutuhkan dapat Perikanan (1980) dalam Danial (1998) dicari dengan menggunakan rumus yang yaitu:

dikemukakan oleh Direktorat Jenderal

$$
L=\frac{(1+s) \times \mathbf{n} \times \mathbf{a} \times \mathbf{h}}{\mathbf{u} \times \mathbf{d}}
$$

Dimana : L : panjang dermaga

h: lama kapal di dermaga (jam)

1 : lebar kapal (m)

$\mathrm{u}$ : produksi per hari (ton)

$\mathrm{s} \quad$ : jarak antar kapal (m)

d: lama fishing trip (jam)

$\mathrm{n}$ : jumlah kapal yang memakai dermaga

a : berat kapal (ton)

Luas kolam pelabuhan dapat dihitung Perikanan (1980) dalam Danial (1998) dengan menggunakan rumus yang yaitu:

dikemukakan oleh Direktorat Jenderal

$$
L=L t+(3 \times n \times l \times b)
$$

Dimana: L : Luas kolam pelabuhan $\left(\mathrm{m}^{2}\right)$

Lt : Luas untuk memutar kapal $\left(\mathrm{m}^{2}\right)$

$\mathrm{N}$ : Jumlah kapal maksimum yang berlabuh

1 : Panjang kapal (m)

b : Lebar kapal (m)

Lt adalah luas untuk memutar kapal, radius pemutarnya minimum satu kali

panjang kapal terbesar. Luas ini dapat dihitung dengan rumus luas lingkaran.

$$
\mathbf{L t}=л \times \mathbf{r}^{2} \quad \text { atau }
$$

$$
\mathbf{L t}=\boldsymbol{\pi} \times \mathbf{l}^{2}
$$

Dimana : Lt : Luas untuk memutar kapal $\left(\mathrm{m}^{2}\right)$

л : 3,14

1 : Panjang kapal terbesar

Kedalaman perairan di wilayah kolam pelabuhan pada saat permukaan air terendah (LLWS) dapat ditentukan dengan menggunakan rumus (Direktorat Jenderal Perikanan, 1980 dalam Danial, 1998), yaitu sebagai berikut :

$$
\mathbf{D}=\mathbf{d}+1 / 2 \mathbf{H}+\mathbf{S}+\mathbf{C}
$$

Dimana : D : Kedalaman perairan $(\mathrm{cm})$ 
d : Draf kapal terbesar $(\mathrm{cm})$

$\mathrm{H} \quad$ : Tinggi gelombang maksimum $(\mathrm{H}$ maks $=50 \mathrm{~cm})$

$\mathrm{S} \quad$ : Tinggi ayunan kapal yang melaju $(10-30 \mathrm{~cm})$

C : Jarak aman dari lunas kapal ke dasar perairan $(25-100 \mathrm{~cm})$

Luas gedung pelelangan dapat dihitung dengan menggunakan rumus yang dikemukakan oleh Yano dan noda (1970) dalam Danial (1998) yaitu :

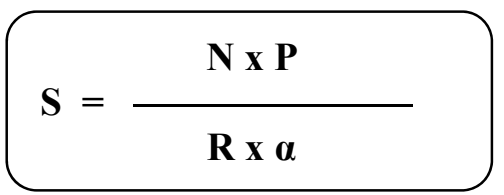

Dimana: $\mathrm{S}$ : Luas gedung pelelangan $\left(\mathrm{m}^{2}\right)$

$\mathrm{N}$ : Jumlah produksi perhari (ton)

$\mathrm{P}$ : Daya tampung produksi $\left(\mathrm{m}^{2} /\right.$ ton $)$

$\alpha$ : Perbandingan ruang lelang dengan gedung lelang $(0,271-0,394)$

$\mathrm{R}$ : Intensitas lelang (1 sampai 2 kali per hari)

Tabel 1. Faktor Daya Tampung Ruangan (P) menurut Jenis Ikan dan Cara Peragaan Jenis Ikan

\begin{tabular}{lcc}
\hline \multicolumn{1}{c}{ Jenis Ikan } & Cara Peragaan & $\begin{array}{c}\text { Faktor Daya } \\
\text { Tampung (P) }\end{array}$ \\
\hline $\begin{array}{l}\text { Jenis ikan kecil, udang cumi } \\
\text { dan lain-lain }\end{array}$ & $\begin{array}{c}\text { 1) Boks ditumpuk 3 } \\
\text { 2) Ditumpuk 10 lapis (dengan } \\
\text { forklift) }\end{array}$ & $\begin{array}{c}1,56 \\
\text { Jenis ikan sedang } \\
\text { tongkol dan lain-lain }\end{array}$ \\
$\begin{array}{l}\text { Jenis ikan besar (tuna) } \\
\text { Sumber : Murdiyanto (2004) dalam Puspitasari (2013) }\end{array}$ & 14 \\
\hline
\end{tabular}

Penentuan arah strategi pengelolaan peningkatan Pangkalan Pendaratan Ikan (PPI) Maccini Baji dilakukan analisis dengan pendekatan analisis SWOT dengan menggunakan analisis IFAS dan EFAS.

\section{HASIL DAN PEMBAHASAN}

Kawasan Pangkalan Pendaratan Ikan Maccini Baji yang terletak di Kelurahan Pundata Baji Kecamatan Labakkang Kabupaten Pangkep menjadi salah satu lokasi pengembangan perikanan tangkap, khususnya di daerah pesisir dan pulau-pulau sekitarnya sudah ada sejak tahun 2008. Kawasan PPI ini berdekatan dengan pelabuhan umum Maccini Baji yang menghubungkan daerah daratan dengan pulau-pulau kecil di sekitarnya hingga luar kabupaten. Adapun fasilitas secara umum yang terdapat di PPI Maccini Baji mencakup tiga jenis fasilitas yang ada di pelabuhan perikanan bertipe D. 
Hasil Evaluasi Fungsi dan Kebutuhan Sarana dan Prasarana

Hasil evaluasi fungsi dan kebutuhan sarana dan prasarana di PPI Maccini Baji, beberapa fasiltas pokok, fungsional dan pendukung sudah tersedia tapi masih sangat minim, dan pada masa yang akan datang perlu dikembangkan lebih jauh. Selengkapnya disajikan sebagai berikut:

Tabel 2. Hasil Analisis Tingkat Kebutuhan Fasilitas Pokok dan Fungsional

\begin{tabular}{lccc}
\hline $\begin{array}{c}\text { Fasilitas Pokok dan } \\
\text { Fungsional }\end{array}$ & $\begin{array}{c}\text { Kondisi } \\
\text { Eksisting }\end{array}$ & $\begin{array}{c}\text { Kebutuhan } \\
\text { Saat ini }\end{array}$ & Keterangan \\
\hline Panjang Dermaga & - & $53,125 \mathrm{~m}$ & $\begin{array}{c}\text { Perlu pembangunan } \\
\text { dermaga }\end{array}$ \\
Revetment & $170 \mathrm{~m}$ & $53,125 \mathrm{~m}$ & Cukup \\
Luas Ruang Lelang TPI & $300 \mathrm{~m}^{2}$ & $103,321 \mathrm{~m}^{2}$ & Cukup \\
LuasKolam Pelabuhan & $10.200 \mathrm{~m}^{2}$ & $7.940,66 \mathrm{~m}^{2}$ & Cukup \\
Kedalaman Pelabuhan & $0-150 \mathrm{~cm}$ & $225 \mathrm{~cm}$ & Kurang \\
SPBN/SPDN & $80.000 \mathrm{Ltr} / \mathrm{bln}$ & $>80.000 \mathrm{Liter} / \mathrm{bln}$ & Kurang \\
Pabrik Es & $1,5-2$ ton/hari & $2-6$ ton/hari & Kurang \\
\hline
\end{tabular}

Sumber: Diolah berdasarkan data yang dikumpulkan di lapangan, 2018.

Fasilitas dermaga PPI Maccini Baji saat ini belum ada, selama ini revetment atau dinding pantai yang berfungsi ganda yakni sebagai tempat nelayan menambatkan kapalnya. Panjang revetment $170 \mathrm{~m}$ yang memanjang sejajar dengan garis pantai. Berdasarkan analisis pemanfaatan fasilitas revetment untuk tempat tambat labuh kapal-kapal di PPI Maccini Baji saat ini dengan jumlah kapal 85 unit berlabuh setiap harinya adalah 53,125 m dan dapat dikategorikan cukup memenuhi dan jika melihat ketersediaan panjang revetment yang ada masih terdapat kelebihan sepanjang 116,875 m. Untuk kondisi panjang revetment demikian sebenarnya bisa menampung sekitar 272 unit kapal nelayan dengan ukuran yang sama yakni 2 GT. Diharapkan ke depannya dibuatkan dermaga atau semacam jalan atau jembatan yang menghubungkan antara pelataran bangunan PPI dengan dermaga yang direncanakan dibangun. Dengan adanya fasilitas tersebut diharapkan dapat mempermudah nelayan melakukan tambat labuh yang lebih dekat dengan ruang lelang TPI dan tempat tinggal nelayan karena pada saat air surut nelayan menambatkan perahunya jauh dari tepi daratan. Hal ini disebabkan dangkalnya kolam labuh yang ada di PPI Maccini Baji.

Dalam menilai kolam pelabuhan, ada dua hal yang akan dianalisis yaitu luas kolam pelabuhan dan kedalaman perairan di wilayah kolam. Luas kolam pelabuhan dihitung berdasarkan panjang kapal terbesar yang memutar dan jumlah kapal maksimum yang berlabuh. Luas kolam pelabuhan PPI Maccini Baji berdasarkan analisis pemanfaatan rumus dari Direktorat Jenderal Perikanan (1980) dalam Danial (1998) yaitu berjumlah 7.940,66 $\mathrm{m}^{2}$ sedangkan kondisi existing yang didapatkan di lokasi adalah 10.200 
$\mathrm{m}^{2}$. Menurut Lubis, 2012 dalam Haro, 2014 bahwa tingkat kebutuhan dapat dikategorikan cukup sebab fungsi pelabuhan perikanan dapat berjalan dengan efektif apabila keadaan fasilitas dan aktifitasnya, maupun besaran fasilitas sesuai atau melebihi kesesuaian dengan kebutuhan saat ini

PPI Maccini Baji memiliki kedalaman kolam pelabuhan $0 \mathrm{~cm}$ pada saat surut terendah, dan draft (d) kapal terbesar yang berlabuh adalah 50-70 cm. Berdasarkan hasil analisis pemanfaatan fasilitas kedalaman kolam pelabuhan PPI Maccini Baji diperoleh nilai sebesar 225 $\mathrm{cm}(\mathrm{D}=2,25 \mathrm{~m})$, sedangkan kondisi eksisting di lokasi untuk kedalaman pada saat surut terendah sangat jauh berbeda yakni tak ada air sama sekali atau $0 \mathrm{~cm}$. Kondisi demikian nelayan masih bisa menyesuaikan periode pasang surut yang terjadi di PPI Maccini Baji atau bila keadaan tidak bisa menunggu maka nelayan dapat berlabuh di Pelabuhan umum yang berbatasang langsung dengan PPI tersebut. Luas kolam labuh PPI yang kami ukur yakni $10.200 \mathrm{~m}^{2}$ bahkan hingga mencapai $17.000 \mathrm{~m}^{2}$ atau sejauh $\pm 100 \mathrm{~m}$ ke arah laut.

Hasil pengukuran gedung pelelangan PPI Maccini Baji didapatkan luas $300 \mathrm{~m}^{2}$ selama pengamatan cukup menampung aktivitas lelang ikan untuk 5 (lima) orang punggawa. Berdasarkan hasil analisis pemanfaatan fasilitas didapatkan nilai sebesar 103,32 $\mathrm{m}^{2}$, yang menunjukkan bahwa luasan ruang lelang saat ini masih sangat cukup untuk menampung hasil tangkapan nelayan yang mendaratkan hasil tangkapannya di PPI
Maccini Baji. Setiap hari rata-rata produksi ikan sebanyak 2 ton, sedangkan luasan ruang gedung lelang saat ini, menampung ikan hingga 5,8 ton

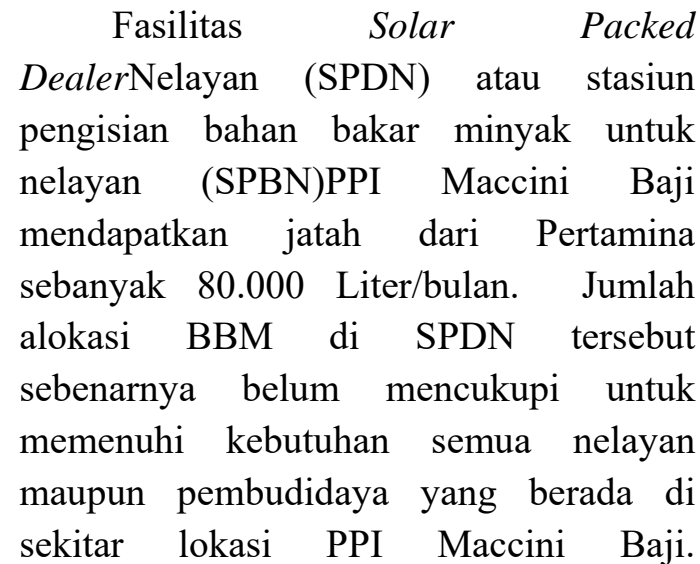
Sementara, untuk pabrik Es yang ada saat ini tidak berfungsi sehingga penyediaan kebutuhan es batu di sekitar tempat itu dilakukan oleh pedagang es swasta. Kebutuhan es ini selain untuk memenuhi permintaan nelayan juga pedagang ikan dan pengusaha rajungan. Jika dilihat dari produksi ikan rata-rata yang ada di TPI Maccini Baji yakni sebesar 2 ton dengan kebutuhan es untuk setiap kilogram ikan adalah sekitar 1-3 kg, maka dalam sehari paling tidak tersedia es sebanyak $2.000 \mathrm{~kg}$ sampai $6.000 \mathrm{~kg}$. Dengan demikian diharapkan adanya pemenuhan kebutuhan es bagi nelayan dan pelaku usaha perikanan lainnya yang ada di PPI Maccini Baji baik oleh pemerintah maupun pihak swasta.

\section{Strategi Pengelolaan PPI Maccini Baji}

Berdasarkan hasil identifikasi faktor internal dan eksternal diperoleh unsurunsur strategi pengelolaan PPI Maccini Baji dalam mengembangkan perannya untuk mensejahterahkan masyarakat 
seperti yang disajikan pada tabel di bawah ini.

Tabel 3. Komponen dan faktor-faktor SWOT peningkatan pengelolaan PPI Maccini Baji

\section{Kekuatan (Strengths) Kelemahan (Weaknesses)}

1. Lokasi PPI yang strategis dan 1. Fasilitas PPI yang masih terbatas dan dekat dengan fishing ground banyak rusak, seperti dermaga, dan usaha tambak MCK, dan kolam labuh

2. Peraturan Daerah (PERDA) 2. Manajemen pelelangan ikan belum No. 22 Tahun 2000 tentang

Retribusi Pasar Grosir dilaksanakan sesuai ketentuan.

3. Potensi sumber daya ikan melimpah

3. Lemahnya modal usaha dalam pengembangan teknologi penangkapan ikan

4. Jumlah nelayan cukup banyak

4. Masih banyak nelayan yang menjual ikan di luar PPI

\section{Peluang (Opportunities) Ancaman (Treaths)}

1. Adanya dukungan pemerintah 1. Keberadaan PPI lain yang lebih pusat untuk lebih dekat dengan Makassar

2. dikembangkan

2. Kebijakan pemerintah yang masih

Permintaan konsumen sangat

3. besar akan ikan laut

Berbatasan dengan pelabuhan

4. penyeberangan antar pulaupulau lemah dalam hal penataan pemasaran ikan oleh nelayan dari wilayah kepulauan

Mutu hasil tangkapan nelayan lebih segar

3. Undang-Undang No. 23 Tahun 2014 tentang Pemerintahan Daerah

4. Maraknya budidaya rumput laut di sekitar jalur masuk pelabuhan

Sumber : Olah Data Primer, 2018.

Setelah mengidentifikasi dan menentukan faktor-faktor internal dan eksternal yang ada sesuai data di atas, maka selanjutnya dilakukan pembobotan dan pemberian rating untuk setiap faktor untuk mengetahui skor masing-masing.

Tabel 4 . Hasil External Strategic Faktors Analysis Summary (EFAS)

\begin{tabular}{|c|c|c|c|c|}
\hline \multicolumn{2}{|c|}{ Faktor-Faktor Strategi Eksternal } & Bobot & Rating & Skor \\
\hline & 1 & 2 & 3 & 4 \\
\hline \multicolumn{5}{|c|}{ Peluang (Opportunities) } \\
\hline $\mathrm{O} 1$ & $\begin{array}{l}\text { Adanya dukungan pemerintah pusat untuk } \\
\text { lebih dikembangkan }\end{array}$ & 0,20 & 4 & 0,80 \\
\hline $\mathrm{O} 2$ & $\begin{array}{l}\text { Permintaan konsumen lumayan besar akan } \\
\text { ikan laut }\end{array}$ & 0,20 & 2 & 0,40 \\
\hline O3 & $\begin{array}{l}\text { Berbatasan dengan pelabuhan penyeberangan } \\
\text { antar pulau-pulau }\end{array}$ & 0,10 & 3 & 0,30 \\
\hline
\end{tabular}




\begin{tabular}{|l|l|c|c|c|}
\hline \multicolumn{2}{|c|}{ Faktor-Faktor Strategi Eksternal } & Bobot & Rating & Skor \\
\hline \multicolumn{2}{|c|}{1} & 2 & 3 & 4 \\
\hline O4 & Mutu hasil tangkapan nelayan lebih segar & 0,20 & 2 & 0,40 \\
\hline Ancaman (Treaths) & & 1 & 0,15 \\
\hline T1 & $\begin{array}{l}\text { Keberadaan PPI lain yang lebih dekat dengan } \\
\text { Kota Makassar }\end{array}$ & 0,15 & 2 & 0,10 \\
\hline T2 & $\begin{array}{l}\text { Kebijakan pemerintah yang masih lemah } \\
\text { dalam hal penataan pemasaran ikan oleh } \\
\text { nelayan dari wilayah kepulauan }\end{array}$ & 0,05 & 2 & 0,20 \\
\hline T3 & $\begin{array}{l}\text { Undang-Undang No. 23 Tahun 2014 tentang } \\
\text { Pemerintahan Daerah }\end{array}$ & 0,10 & 2 & 0,20 \\
\hline T4 & $\begin{array}{l}\text { Maraknya budidaya rumput laut di sekitar } \\
\text { jalur masuk pelabuhan PPI }\end{array}$ & 0,05 & 4 & $\mathbf{2 , 5 5}$ \\
\hline \multicolumn{2}{|c|}{ Total } & 1 & & \\
\hline
\end{tabular}

Sumber :Olahan Data Primer, 2018

Hasil analisis EFAS di atas, menunjukkan faktor Peluang (Opportunities) memiliki nilai lebih besar yaitu 1,9 dibanding nilai Ancaman (Treaths) yaitu 0,65. Hal ini dapat diartikan bahwa peluang yang dimiliki dapat memanfaatkan faktor peluang yang ada untuk mengatasi faktor ancaman. Faktor pengembangan strategi berdasarkan perhitungan dari nilai rating faktor eksternal ialah pengurangan antara faktor Peluang (Opportunities) dan Ancaman (Treaths) yaitu 1,9-0,65 =1,25 yang dijadikan sebagai sumbu Y.Sementara untuk analisis IFAS, menunjukkan faktor Kekuatan (Strengths) memiliki nilai lebih besar yaitu 2,05 dibanding nilai Kelemahan (Weaknesses) yaitu 0,65 . Hal ini dapat diartikan bahwa kekuatan yang dimilki dapat memaksimalkan faktor kekuatan yang ada untuk meminimalkan faktor- faktor kelemahannya. Faktor pengembangan strategi berdasarkan perhitungan dari nilai rating faktor eksternal ialah pengurangan antara faktor Peluang (Opportunities) dan Ancaman (Treaths) yaitu 2,05 - 0,65 =1,4 yang dijadikan titik koordinat pada sumbu $\mathrm{X}$.

Tabel 5. Hasil Internal Strategic Factors Analysis Summary (IFAS)

\begin{tabular}{|c|c|c|c|c|}
\hline & Faktor-Faktor Strategi Internal & Bobot & Rating & Skor \\
\hline & 1 & 2 & 3 & 4 \\
\hline \multicolumn{5}{|c|}{ Kekuatan (Strengths) } \\
\hline $\mathrm{S} 1$ & $\begin{array}{l}\text { Lokasi PPI yang strategis dan dekat dengan } \\
\text { fishing ground dan usaha tambak }\end{array}$ & 0,20 & 4 & 0,80 \\
\hline $\mathrm{S} 2$ & $\begin{array}{l}\text { Peraturan Daerah (Perda) No. } 22 \text { Tahun } 2000 \\
\text { tentang Retribusi Pasar Grosir }\end{array}$ & 0,10 & 2 & 0,20 \\
\hline S3 & Potensi sumber daya ikan cukup besar & 0,15 & 3 & 0,45 \\
\hline
\end{tabular}




\begin{tabular}{|c|c|c|c|c|}
\hline & Faktor-Faktor Strategi Internal & Bobot & Rating & Skor \\
\hline & 1 & 2 & 3 & 4 \\
\hline S4 & Jumlah nelayan yang cukup besar & 0,20 & 3 & 0,60 \\
\hline \multicolumn{5}{|c|}{ Kelemahan (Weaknesses) } \\
\hline W1 & $\begin{array}{l}\text { Fasilitas PPI yang masih terbatas dan banyak } \\
\text { rusak, seperti dermaga/revetment, kolam } \\
\text { labuh dan MCK }\end{array}$ & 0,20 & 1 & 0,20 \\
\hline W2 & $\begin{array}{l}\text { Manajemen pelelangan ikan belum } \\
\text { dilaksanakan sesuai ketentuan yang berlaku }\end{array}$ & 0,05 & 2 & 0,10 \\
\hline W3 & $\begin{array}{l}\text { Lemahnya modal usaha untuk penerapan } \\
\text { tekhnologi penangkapan yang lebih canggih }\end{array}$ & 0,05 & 3 & 0,15 \\
\hline W4 & $\begin{array}{l}\text { Masih banyak nelayan yang menjual ikannya } \\
\text { di luar PPI }\end{array}$ & 0,05 & 4 & 0,20 \\
\hline & Total & 1 & & 2,70 \\
\hline
\end{tabular}

Sumber :Olahan Data Primer, 2018

Hasil kualitatif antara faktor internal dan faktor eksternal akan diformulasikan pada diagram SWOT agar dapat diketahui letak kuadrannya. Setelah nilai tertimbang dijabarkan dalam diagram maka diketahui bahwa konsep berada pada posisi kuadran I atau strategi agresif.

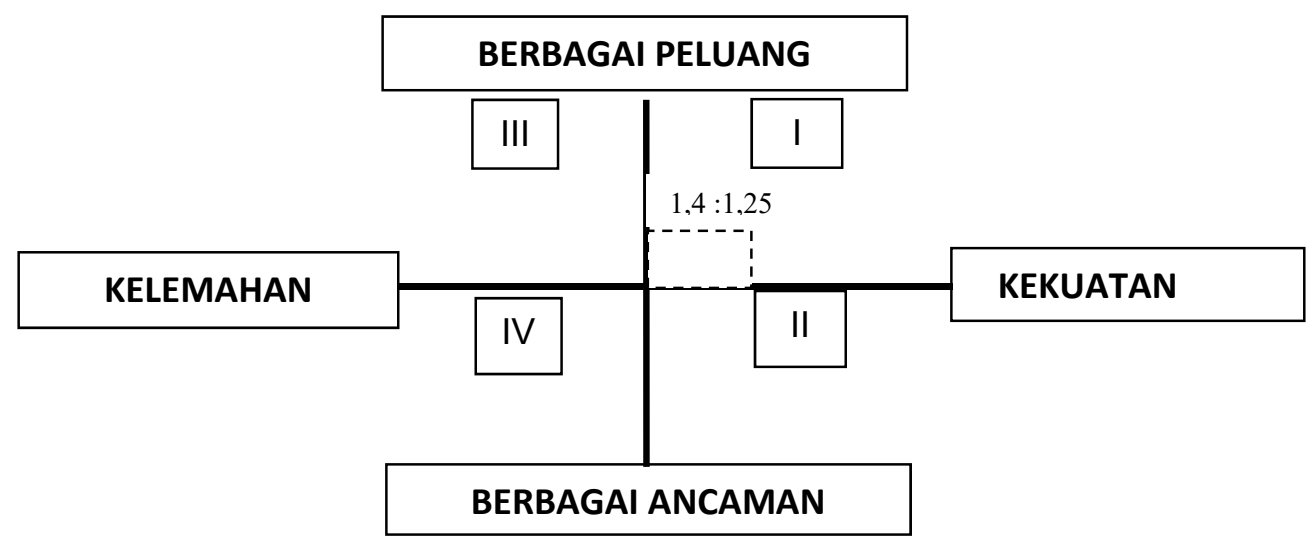

Gambar 1. Posisi Pengelolaan dan Pengembangan PPI Maccini Baji

Strategi yang harus diterapkan benar memaksimalkan setiap kekuatan dalam kondisi ini adalah mendukung yang dimiliki dengan memanfaatkan kebijakan pertumbuhan yang agresif peluang yang ada dalam pengembangan (growth oriented strategy). Ini PPI Maccini Baji ke depannya. merupakan situasi yang sangat Selanjutnya dibuat model matriks SWOT menguntungkan. PPI tersebut memiliki untuk memperoleh strategi-strategi dalam peluang dan kekuatan yang besar sehingga pengelolaan dan pengembangan PPI dapat menentukan strategi yang benar- Maccini Baji. 
Tabel 6. Matriks SWOT untuk Strategi Pengelolaan PPI Maccini Baji

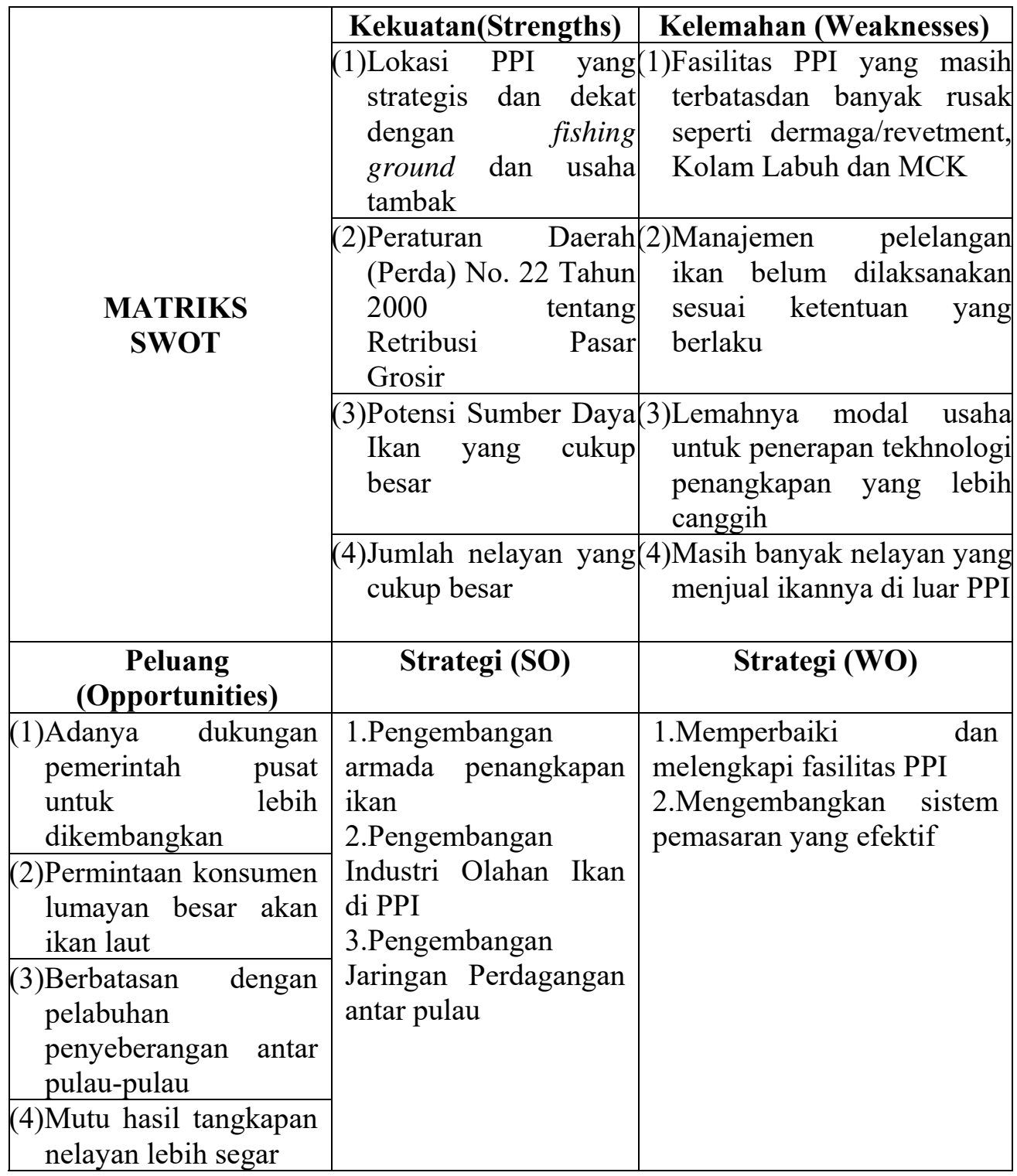




\begin{tabular}{|c|c|c|}
\hline Ancaman (Treaths) & Strategi (ST) & Strategi (WT) \\
\hline \begin{tabular}{|lr} 
(1)Keberadaan & PPI lain \\
yang lebih & dekat \\
dengan & Kota \\
Makassar &
\end{tabular} & \multirow{4}{*}{$\begin{array}{lr}\text { 1.Menata } & \text { dan } \\
\text { menetapkan } & \text { kebijakan } \\
\text { pemerintah } & \text { yang } \\
\text { mengatur } & \text { sistem } \\
\text { pemasaran } & \text { nelayan } \\
\text { kepulauan } & \\
\text { 2.Menata } & \text { lokasi } \\
\text { budidaya rumput laut }\end{array}$} & \multirow{4}{*}{$\begin{array}{lr}\text { 1.Pengembangan } & \text { dan } \\
\text { perbaikan sistem layanan } \\
\text { dan kenyamanan bagi } \\
\text { nelayan } \\
\text { memanfaatkan PPI } \\
\begin{array}{l}\text { 2. Pengembangan } \\
\text { perizinan yang terintegrasi. }\end{array}\end{array}$} \\
\hline $\begin{array}{l}\text { (2)Kebijakan pemerintah } \\
\text { yang masih lemah } \\
\text { dalam hal penataan } \\
\text { pemasaran ikan oleh } \\
\text { nelayan dari wilayah } \\
\text { kepulauan }\end{array}$ & & \\
\hline $\begin{array}{l}\text { (3)UU No. } 23 \text { Tahun } \\
2014 \text { ttgPemerintahan } \\
\text { Daerah }\end{array}$ & & \\
\hline $\begin{array}{l}\text { (4)Maraknya budidaya } \\
\text { rumput laut di sekitar } \\
\text { jalur masuk pelabuhan } \\
\text { PPI }\end{array}$ & & \\
\hline
\end{tabular}

Strategi-strategi di atas selanjutnya diurutkan menurut peringkat berdasarkan jumlah skor unsur-unsur penyusunnya. Diperoleh 9 (sembilan) strategi pengelolaan yang dijabarkan dalam rencana program yang arah kebijakannya dilakukan untuk meningkatkan pengelolaan PPI Maccini Baji ke depan, antara lain :1.Pengembangan armada penangkapan ikan; 2. Pengembangan jaringan perdagangan antar pulau; 3 . Pengembangan industri olahan ikan di PPI; 4. Menata dan menetapkan kebijakan pemerintah yang mengatur sistem pemasaran nelayan kepulauan; 5. Memperbaiki dan melengkapi fasilitas PPI; 6. Menata lokasi budidaya rumput laut; 7. Mengembangkan sistem pemasaran yang efektif; 8 . Pengembangan dan perbaikan sistem layanan dan kenyamanan bagi nelayan yang memanfaatkan PPI; dan 9. Pengembangan sistem perizinan yang terintegrasi.

\section{KESIMPULAN}

Berdasarkan hasil penelitian dan analisis data yang telah dilakukan, maka didapatkan kesimpulan bahwa untuk peningkatan fungsi sarana dan prasarana PPI Maccini Baji terutama pada fasilitas kolam labuh tidak bisa berfungsi optimal dan membutuhkan pengerukan, sementara untuk fasilitas dermaga saat ini masih berupa revetment dan perlu dilakukan pembangunan dermaga. Pabrik Es dan SPDN juga masih memerlukan penambahan stok untuk menyuplai kebutuhan di sekitar PPI. Sementara, untuk strategi pengelolaan PPI Maccini Baji ada 9 (sembilan) langkah strategis yang bisa ditempuh.

\section{SARAN}

Adapun saran yang dapat direkomendasikan dari hasil penelitian ini yakni ; perlunya penelitian lanjutan untuk 
mengkaji terkait pembangunan jalan atau jembatan yang menghubungkan antara pelataran bangunan PPI dengan dermaga yang direncanakan dibangun, dan melakukan pembangunan pelindung pantai (breakwater) agar dapat memberikan manfaat perlindungan kapal-kapal nelayan dan juga bangunan di kawasan PPI dari hempasan ombak terutama pada saat musim barat.

\section{UCAPAN TERIMA KASIH}

Penulis mengucapkan terima kasih kepada Pemerintah Kabupaten Pangkep yang telah memberikan dukungan pembiayaan untuk melaksanakan penelitian tesis ini dan para reviewer yang telah banyak memberikan masukan dan komentar untuk memperbaiki tulisan ini.

\section{DAFTAR PUSTAKA}

Danial. 1998. Studi Tentang Kapasitas Pelabuhan Perikanan dan Kemungkinan Pengembangannya di Kota Madya Ujung Pandang Provinsi Sulawesi Selatan. Tesis. Program Pascasarjana Institut Pertanian Bogor. Bogor.
Dinas Perikanan Kabupaten Pangkajene dan Kepulauan. 2015. Profil Pelaku Usaha Dinas Kelautan dan Perikanan Kabupaten Pangkep. Pangkep. Sulawesi Selatan

Haro T.B.S, Surbakti S, dan Nurhasanah. 2014. Kajian Peran dan Strategi Pengelolaan Pangkalan Pendaratan Ikan Hamadi. Jurnal Manajemen Perikanan dan Kelautan Vol.1 No.1 artikel 9.

Puspitasari N, Irnawati R, Susanto A. 2013. Strategi Pengembangan Pelabuhan Perikanan Nusantara Karangantu Kota Serang Provinsi Banten. Jurnal Ilmu Pertanian dan Perikanan. Vol. 2 No.2 hal : 159 169. ISSN 2302-6308. Jurusan Perikanan Fakultas Pertanian Universitas Sultan Ageng Tirtayasa. 